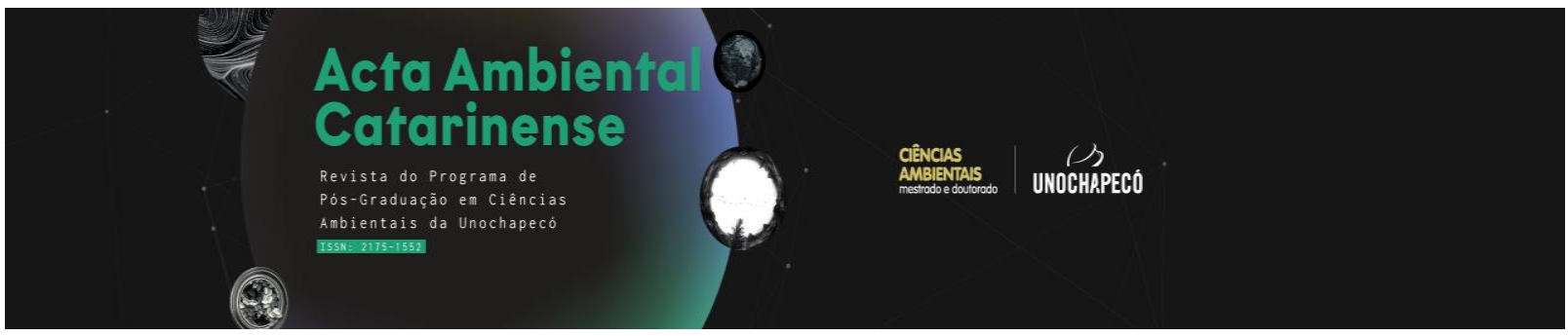

\title{
ANÁLISE DO POTENCIAL BIOCATALÍTICO DE LIPASE DE CANDIDA RUGOSA IMOBILIZADA EM DIFERENTES SUPORTES
}

Adriano da Silva ${ }^{1 *}$; Rafael José Resende ${ }^{2}$; Tamires Cristina Costa ${ }^{1}$; Bárbara Viviane Oliveira de Sousa ${ }^{2}$; Anderson Kenedy Santos ${ }^{3}$; Braz de Souza Marotti ${ }^{4}$; Saulo Luís da Silva ${ }^{5,6,7}$; Adriano Cancelier ${ }^{8}$; Daniel Bonoto Gonçalves ${ }^{2}$

\begin{abstract}
Resumo
Neste trabalho é avaliado o potencial biocatalítico da lipase de Candida rugosa (LCR) imobilizada em diferentes suportes: carvão ativado, gesso comercial e sílica gel, visando a produção de biodiesel. O método de imobilização por adsorção foi utilizado na imobilização da LCR nos suportes. A eficiência de imobilização expressa em termos da razão entre a atividade do complexo suporte-LCR e atividade da enzima livre, foram estimados, fornecendo eficiência de $89 \%$ para o carvão ativado-LCR, 62\% para a sílica gel-LCR e $48 \%$ para o gesso-LCR. O complexo carvão ativado-LCR forneceu o maior índice de acidez. A análise por cromatografia de camada delgada do biodiesel produzido por este complexo apresentou fatores de retenção e ordem de eluição dos acilgliceróis compatíveis com a literatura, indicando um potencial deste complexo para a produção de biodiesel.
\end{abstract}

Palavras-chave: Carvão ativado, sílica gel, Lipase, biocatálise, biodiesel.

\footnotetext{
${ }^{1}$ Departamento de Engenharia Química e Engenharia de Alimentos, UFSC - Universidade Federal de Santa Catarina, Florianópolis, SC, 88040-900, Brasil.

${ }^{2}$ Universidade Federal de São João del-Rei, Campus Centro Oeste Dona Lindu, Av. Sebastião Gonçalves Coelho, 400 Chanadour - 35501-296 - Divinópolis-MG, Brasil.

${ }^{3}$ Departamento de Fisiologia e Biofísica, Instituto de Ciências Biológicas - Universidade Federal de Minas Gerais, Belo Horizonte, MG, 31270-901, Brasil.

${ }^{4}$ Departamento de Biotecnologia Industrial, Escola de Engenharia de Lorena, Universidade de São Paulo-USP, Estrada Municipal do Campinho, s/n, Bairro Campinho, Lorena, SP, 12602-810, Brasil.

${ }^{5}$ College of Biochemistry and Pharmacy, Faculty of Chemical Sciences, University of Cuenca, Cuenca / Azuay, Equador.

${ }^{6}$ Chemistry and Biochemistry Department, Faculty of Sciences, University of Porto, Porto, Portugal.

${ }^{7} \mathrm{LAQV}$ - REQUIMTE, University of Porto, Porto, Portugal.

${ }^{8}$ Departamento de Engenharia Química, UFSM - Universidade Federal de Santa Maria, Av. Roraima 1000, Bairro Camobi, CEP 97.105-900, Santa Maria, RS, Brasil.

*E-mail: adrianodasilva.ufsj@gmail.com

DOI 10.24021/raac.v18i1.5505 


\begin{abstract}
His work assessed the biocatalytic potential of the immobilized Candida rugosa lipase (CRL) in different supports: activated carbon, commercial plaster and silica gel aiming at the production of biodiesel. The adsorption immobilization method was used to immobilize CRL in supports. The immobilization efficiency expressed in terms of the ratio between the activity of the CRL complex support and the activity of free enzyme were estimated, resulting in $89 \%$ for activated carbon CRL, $62 \%$ for silica gel CSF and $48 \%$ for plaster-CRL. The complex activated carbon-LCR provided the highest acidity index. The analysis by thin layer chromatography of the biodiesel produced by this complex showed retention factor and elution of acylglycerols compatible with literature data indicating a relevant potential of this complex to produce biodiesel
\end{abstract}

Keywords: Activated carbon, silica gel, Lipase, biocatalysis, biodiesel

\section{INTRODUÇÃ̃o}

Diante dos problemas ambientais gerados pelo aumento das emissões de gases poluentes produzidos com a queima de combustíveis fósseis, é crescente em todo o mundo a busca por matérias-primas renováveis, bem como por fontes alternativas de energia. $\mathrm{O}$ crescente aumento na demanda por energia é uma preocupação mundial (BP p.1.c, 2019). Aproximadamente $80 \%$ da matriz energética mundial é baseada em combustíveis fósseis (petróleo, gás natural e carvão), e uma forma de diminuir esta dependência está em incentivar tanto a produção, como o uso de combustíveis provenientes de fontes renováveis e com isso reduzir o impacto ambiental das altas taxas de emissão de dióxido de carbono na atmosfera (GEBREMARIAM et al., 2017; CARDOSO et al., 2020).

Diante desta demanda é crescente em todo o mundo a busca por matérias-primas renováveis, bem como por fontes alternativas de energia, e o biodiesel produzido a partir de óleos vegetais pode atender plenamente aos requisitos ambientais atuais, e quando misturado ao diesel de petróleo, induz uma redução significativa da emissão de enxofre e sólidos particulados na atmosfera (SOUZA, 2006; DI SERIO, 2007). Muitas pesquisas têm se concentrado no caráter renovável dos insumos para a produção deste biocombustível (SUAREZ et al., 2007).

Uma estratégia amplamente utilizada na produção de biodiesel é aquela que forma o combustível como ésteres metílicos a partir de ácidos graxos. Nesta reação os ésteres metílicos são obtidos através da reação de transesterificação dos triglicerídeos de óleos vegetais com metanol por meio do uso de catalisadores (FUKUDA et al., 2001). Esta reação pode ser realizada tanto através de catalise básica, como catalise ácida, e ainda catalise enzimática (biocatálise) (ALI e HANNA, 1994; FANGRUI e MILFORD, 1999; THANGARAJ et al., 2019; CARDOSO et al., 2020).

A reação de transesterificação utilizando-se a catálise básica possui vários inconvenientes como, por exemplo, a baixa seletividade do catalisador, a ocorrência de reações de saponificação, o que dificulta a purificação dos ésteres formados (KARAOSMANOGLU et al., 1996). Já a catálise ácida necessita de condições reacionais extremas como valores elevados de temperatura e pressão (ABREU, 2013). Este comportamento tem impulsionado as pesquisas por novos catalisadores, específicos e recuperáveis, para a reação de transesterificação para produção de biodiesel (SOUMANOU e BORNSCHEUER, 2003; ATADASHI et al., 2013; TALHA e 
SULAIMAN, 2016; GEBREMARIAM et al., 2017; CARDOSO et al., 2020).

O potencial biotecnológico da catálise enzimática possui grande vantagens em relação a outros tipos de catalises como, possibilidade de utilização de matérias primas com elevados teores de ácidos graxos, condições brandas de temperatura e pressão , além de possuírem elevada especificidade e seletividade pelos substratos e raramente produzem reações colaterais que levam ao desperdício (HASAN et al., 2006; ARANTE, 2008; BASSO e SERBAN, 2019). Adicionalmente, os processos catalisados por enzimas apresentam alta eficiência de conversão, além de serem ambientalmente sustentáveis (LI et al., 2006; ARANTES, 2008; ROBLES-MEDINA et al., 2009; CARDOSO et al., 2009; SOUZA et al., 2015). Estas características têm impulsionado o interesse da comunidade científica no desenvolvimento de tecnologias enzimáticas para a produção de biodiesel.

Lipases em sua forma livre, sofrem um processo chamado desnaturação ao entrar em contato com elevadas concentrações de álcoois de cadeia curta (metanol e etanol), condições essas, necessárias para a produção de biodiesel. Quando imobilizadas em suportes sólidos, o suporte funciona como uma proteção aumentando o rendimento da reação (ABREU, 2013).

As aplicações industriais de lipases apresentam desafios a serem superados principalmente com relação ao custo elevado. Como regra geral, o custo do catalisador representa alguns pontos percentuais dos custos totais de produção e essa restrição, em muitos casos, representa um gargalo para a sustentabilidade econômica de síntese biocatalisada em escala industrial (CANTONE et al., 2013). Isso pode ser superado empregando técnicas de imobilização em suportes sólidos. A imobilização facilita a separação dos produtos e pode fornecer um maior contato entre os componentes do complexo enzima/substrato usando vários configurações do reator (MENDES et al., 2011).

A imobilização também apresenta vantagens relacionadas ao aspecto ambiental. Quando encapsuladas em suportes sólido, expande suas aplicações até remoção de poluentes em efluentes industriais aquosos (CANTONE et al., 2013). Além disso, o ciclo de vida da produção industrial de enzimas apresenta algumas características negativas com relação a sustentabilidade (elevado número de etapas "downstream" e elevado consumo de água). Apesar de permitirem a produção sustentável de diversos produtos, a produção das enzimas em si, pode possuir etapas onde a sustentabilidade ainda é um desafio. Logo, a imobilização enzimática permite o reciclo dessas enzimas e sua reutilização em novas reações bioquímicas, diminuindo assim, o consumo desses biocatalisadores (JEGANNATHAN; NIELSEN, 2013). Dessa forma, a produção do biodiesel catalisada por enzimas imobilizadas em suportes sólidos tem impulsionado muitos estudos visando encontrar meios de recuperar e reutilizar esse tipo de catalisador (SOARES et al., 1999; ZIVKOVIC et al., 2015; THANGARAJ et al., 2019).

Segundo DALLA-VECCHIA et al., (2004), para ser efetivo a imobilização da enzima no suporte deve deixar o sítio ativo da enzima acessível aos substratos e manter sua atividade por longo período de tempo, o que pode eficazmente reduzir o custo em aplicações na indústria. $\mathrm{O}$ processo de imobilização de enzimas em um suporte envolve, basicamente, a escolha do suporte e o método de imobilização que resulte em um preparado imobilizado ativo e estável.

A literatura tem abordado os diferentes métodos de imobilização de enzimas e suas aplicações industriais (MUSTRANTA et al., 1993; TISCHER e KASCHE, 1999; NGUYEN e KIM, 2017; BASSO e SERBAN, 2019). A principal característica que interfere na escolha do tipo de suporte para imobilização é sua afinidade ou não pela água, 
ou seja, seu caráter hidrofílico ou hidrofóbico (DALLA-VECCHIA et al., 2004; CARDOSO et al., 2009).

Um dos principais problemas associados ao uso de catalisadores heterogêneos enzimáticos é a perda de sua atividade catalítica, principalmente devido a mudança da estrutura tridimensional de seu sitio ativo o que leva a um impedimento estérico que impede que o substrato possa interagir com a enzima (OZYILMAZ, 2009). Embora a catálise enzimática utilizando enzima (lipase) imobilizada se apresente como uma das rotas promissoras para se produzir biodiesel, por propiciar uma cadeia completa de insumos renováveis, este campo da biotecnologia ainda carece de estudos. Melhores sistemas de lipases imobilizadas com características de serem mais eficazes, mais duráveis e de menor custo ainda são de grande demanda para o processo de síntese de biodiesel (ATADASHI et al., 2013; BASSO e SERBAN, 2019).

Neste contexto, o presente trabalho apresenta uma análise sobre os métodos adsorção utilizados na imobilização da lipase de Candida rugosa em diferentes suportes: carvão ativado, sílica gel e gesso. Uma avaliação do potencial biocatalítico dos complexos formados (suporte-LCR) foi realizada determinando a atividade hidrolítica da enzima imobilizada no suporte em relação a atividade hidrolítica da enzima livre. Este trabalho contribui para o desenvolvimento da biocatálise enzimática aplicada à produção de biocombustíveis, avaliando o potencial de diferentes suportes para imobilização de lipases, percorrendo os passos iniciais para um futuro desenvolvimento tecnológico de um biocatalisador para a produção de biodiesel.

\section{Material e Métodos}

\subsection{Materiais}

A lipase fúngica isolada de Candida rugosa (tipo VII) foi adquirida da SigmaAldrich Chemical Co. (St. Louis, MO, EUA).
A atividade declarada pelo fabricante desta enzima na hidrólise do p-nitrofenilpalmitato é de $700 \mathrm{U} / \mathrm{mg}$. Todos os reagentes utilizados foram de grau analítico da Sigma-Aldrich Chemical. Os óleos vegetais utilizados como fontes de triacilgliceróis foram, o óleo de soja refinado e azeite de oliva extra virgem comercial. Gesso comercial, sílica gel (Merck) e carvão ativado (Carbomafra) produzido a partir da casca de coco foram utilizados como suporte para a imobilização da enzima.

\subsection{Tratamento dos suportes}

Os suportes para imobilização por adsorção da LCR foram adequadamente preparados. Para o carvão ativado adicionouse $0,7 \mathrm{~g}$ deste suporte em $20 \mathrm{~mL}$ de solução de $\mathrm{HNO}_{3}(0,1 \mathrm{M})$ e $\mathrm{HCl}(0,1 \mathrm{M})$. A mistura foi mantida sob agitação constante por quatro horas, em temperatura ambiente. Após este tratamento, o suporte foi lavado com água destilada e levado à secagem em estufa. No caso da sílica gel, adicionou-se $1 \mathrm{~g}$ de sílica em $10 \mathrm{~mL}$ de solução de $\mathrm{HCl}$ 1,0 M. A mistura foi mantida sob agitação $(4 \quad h)$ e posteriormente foi filtrada, lavada com água destilada e levado à secagem em estufa. $\mathrm{O}$ gesso comercial $(4,9 \mathrm{~g})$ foi adicionado em $15 \mathrm{~mL}$ de água destilada e mantido em agitação constante até sua completa homogeneização. Em seguida a mistura foi seca e calcinada a $800{ }^{\circ} \mathrm{C}, 1 \mathrm{~g}$ do material tratado foi adicionado em $10 \mathrm{~mL}$ de solução de $\mathrm{HCl}$ 1,0 M e, mantido em agitação constante por quatro horas. Posteriormente o filtrado foi lavado com água destilada e levado à secagem em estufa.

\subsection{Determinação da atividade hidrolítica da lipase}

O efeito da imobilização sobre a atividade catalítica da lipase de Candida rugosa foi investigado comparando-se a atividade da enzima imobilizada com a atividade da enzima em solução. As medidas da atividade enzimática da enzima livre e 
imobilizada foram determinadas usando o substrato p-nitrofenil palmitato ( $\mathrm{p}$-NPP, massa molecular de $377,5 \mathrm{~g} / \mathrm{mol}$ ), de acordo com metodologia descrita por PENCREAC'H e BARATTI (1996) e PENCREACH et al. (2002), (MUSTRANTA et al, 1993; SOARES et al.,1999; BARBOSA et al., 2014).

Os experimentos para avaliação da atividade enzimática foram realizados através da reação de transesterificação enzimática do óleo de soja e etanol. Em frascos Erlenmeyer de $50 \mathrm{~mL}$ adicionou-se $6 \mathrm{~g}$ de óleo, $1,5 \mathrm{~g}$ de etanol e $15 \mathrm{~mL}$ de água. Os frascos com as misturas foram incubados a $37^{\circ} \mathrm{C}$ em diferentes tempos $(2,4,6$ e 8 h), em estufa termostatizada com agitação orbital. Após cada período de incubação, a reação foi paralisada pela adição de $15 \mathrm{~mL}$ de uma mistura de acetona e etanol (1:1). Os ácidos graxos liberados foram titulados utilizando um titulador potenciométrico 887 Titrino Plus Metroh com solução de $\mathrm{KOH} 0,35 \mathrm{M}$, e fenolftaleína como indicador. Os resultados foram expressos em índice de acidez, que representa a quantidade em $\mathrm{mg}$ de base necessárias para neutralizar $1 \mathrm{~g}$ de ácido, no caso ácido graxo livre.

\subsection{Eficiência de imobilização}

O rendimento do acoplamento ou eficiência de imobilização ( $\eta \%)$, expressa por uma razão entre a atividade da enzima imobilizada e a atividade da enzima livre, foi estimada de acordo com a Equação 1 (SOARES et al., 1999; BRUNO et al., 2008):

$$
\eta(\%)=\left(\frac{A_{i}}{A_{s}}\right) * 100
$$

onde: $A_{i}$ representa a atividade da enzima imobilizada, $A_{s}$ a atividade da enzima em solução.

\subsection{Ponto de carga zero do carvão ativado}

A análise do $\mathrm{pH}$ PCZ permite prever a carga na superfície do adsorvente em função do $\mathrm{pH}$ e, desta forma, avaliar qual a faixa de pH na qual a etapa de impregnação deve ser realizada. Segundo ELLIOTT e HUANG (1981), os processos de adsorção são fortemente dependentes do $\mathrm{pH}$, visto que afeta a carga superficial do adsorvente, bem como o grau de ionização e as espécies do adsorbato. No ponto crítico do $\mathrm{pH}$, a quantidade de cargas negativas equilibra-se exatamente com a quantidade de cargas positivas, tendo-se, portanto, carga zero ou ponto isoelétrico. Este é característico para certos materiais (PARK e REGALBUTO, 1995).

O ponto de carga zero é definido como sendo o $\mathrm{pH}$ no qual a carga superficial do material é neutra, e a medição de onze pontos é o procedimento mais comum e usado para obter o pHPCZ (REGALBUTO e ROBLES, 2004). Os onze pontos de $\mathrm{pH}$ usados foram: 1 , $2,3,4,5,6,7,8,9,10,11$. Os experimentos foram realizados em frascos Erlenmeyers de $100 \mathrm{~mL}$, contendo $50 \mathrm{~mL}$ de solução de $\mathrm{NaCl}$ $0,10 \mathrm{M}$ nos diferentes pHs ajustados com soluções de $\mathrm{HCl}$ 0,5 M e NaOH 0,5 M. Após os ajustes de $\mathrm{pHs}$, foram adicionados $0,10 \mathrm{~g}$ de amostras do carvão e mantidos sob agitação a $100 \mathrm{rpm}$ em shaker horizontal por $24 \mathrm{~h}$ a $25^{\circ} \mathrm{C}$. Em seguida as soluções foram filtradas e amostras do filtrado recolhidas para análises de $\mathrm{pH}_{\text {Final }}$ com o auxílio de um pHmetro de bancada (SILVA et al, 2016; PERILLI et al, 2014; CAMPOS et al, 2014). As análises foram realizadas em triplicata

A análise do $\mathrm{pH}$ PCZ permite prever a carga na superfície do adsorvente em função do $\mathrm{pH}$ e, desta forma, avaliar qual a faixa de $\mathrm{pH}$ na qual a etapa de impregnação deve ser realizada. Segundo ELLIOTT e HUANG (1981), os processos de adsorção são fortemente dependentes do $\mathrm{pH}$, visto que afeta a carga superficial do adsorvente, bem como o grau de ionização e as espécies do adsorbato. No ponto crítico do $\mathrm{pH}$, a quantidade de cargas negativas equilibra-se exatamente com a quantidade de cargas positivas, tendo-se, portanto, carga zero ou ponto isoelétrico. Este é característico para certos materiais (PARK e REGALBUTO, 1995). 


\subsection{Análise morfológica do carvão ativado}

A morfologia do carvão ativado foi caracterizada através do método de Brunauer, Emmett e Teller (BET) utilizando o equipamento Autosorb-1, Quantachrome Instruments, obtendo-se dados de área superficial, volume do poro e tamanho do poro. Estas análises foram realizadas no Laboratório da Central de Análises do Departamento de Engenharia de Química e Engenharia de Alimentos da UFSC.

A microestrutura do carvão ativado foi analisada no Laboratório de Caracterização Microestrutural - LCM - UFSC, utilizando o microscópio eletrônico de varredura, modelo Philips30. As amostras foram fixadas em fita de carbono e recobertas com ouro, segundo procedimento do laboratório.

\subsection{Imobilização da lipase de Candida rugosa}

O processo de imobilização, por adsorção, da lipase tipo VII de Candida rugosa (LCR) nos suportes selecionados, consistiu do contato direto da solução enzimática com os suportes tratados (ZIVKOVIC et al., 2015; ZARE et al., 2018). Inicialmente, uma solução estoque de lipase $(0,033 \mathrm{~g} / \mathrm{mL})$ foi preparada dissolvendo lipase em pó em PBS (fosfato salino tamponado) $(0,1 \mathrm{M} ; \mathrm{pH} 7,0)$. Após a dispersão de $1 \mathrm{~g}$ de suporte sólido (em 0,5 mL de PBS, $5 \mathrm{~mL}$ da solução de lipase foi adicionada a esta suspensão. As misturas foram mantidas a $25^{\circ} \mathrm{C}$ sob agitação orbital por $24 \mathrm{~h}$. Após este tempo o complexo enzima-suporte foi recuperada por filtração, lavado e armazenado sob refrigeração a $-2{ }^{\circ} \mathrm{C}$ até seu uso na reação de transesterificação.

\subsection{Produção de biodiesel e análise de cromatografia de camada delgada (CCD)}

A produção de biodiesel utilizando a enzima imobilizada foi avaliada pela reação de transesterificação do óleo de soja e metanol em uma proporção em volume $(1: 2, \mathrm{v} / \mathrm{v}) \mathrm{em}$ n-hexano a $37^{\circ} \mathrm{C}$, com agitação orbital por 8 DOI 10.24021/raac.v18i1.5505 horas. Alíquotas foram retiradas ao final da reação para posterior análises cromatográficas em camada delgada.

Soluções de biodiesel e óleo de soja foram separadamente preparadas e aplicadas lado a lado na cromatoplaca de sílica gel, a qual foi eluída com uma a mistura de ácido acético: acetato de etila: n-hexano em uma proporção em volume $(0,1: 1: 200, \mathrm{v} / \mathrm{v})$. Como material controle foi utilizado óleo de soja comercial e as placas cromatográficas foram reveladas em vapor de iodo (adaptada de HAWASH et al., 2009).

A distância das corridas foi avaliada empregando um paquímetro e os fatores de retenção foram calculados seguindo a Equação 2.

$$
R_{f}=\frac{d s}{d m}
$$

onde: $R_{f}$ representa o fator de retenção, $d s$ a distância percorrida pela amostra e $d m$ a distância total da placa cromatográfica.

\section{Resultados E DiscuSsão}

\subsection{Atividade hidrolítica da enzima}

Os resultados da hidrólise de triacilglicerol em ácidos graxos livres e glicerol expressos em índice de acidez, tanto para a enzima livre, como para os complexos suporte-LCR são apresentados na Figura 1.

Figura 1. Índice de acidez de enzima livre para os complexos enzima-suporte.

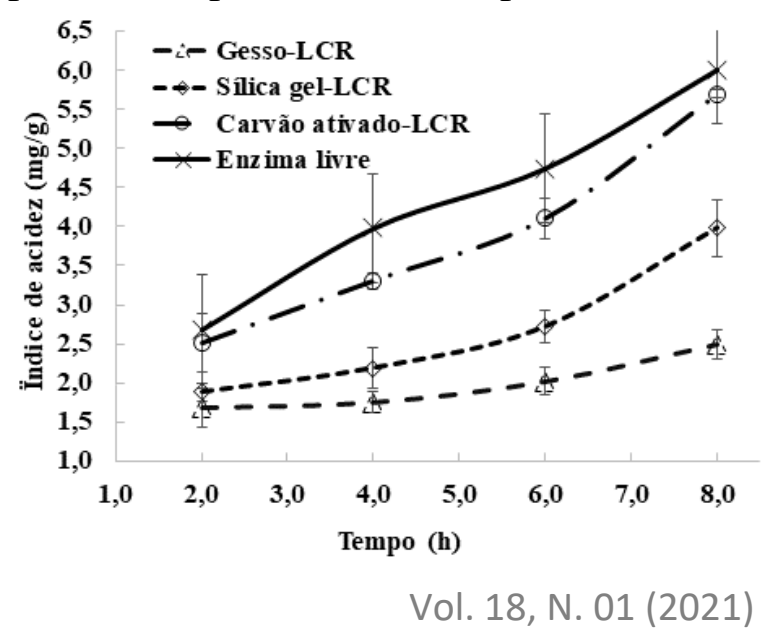


- A atividade da lipase livre foi considerada controle para as análises. Os dados expressos como índice de acidez correlacionada a quantidade em $\mathrm{mg}$ de base necessárias para neutralizar $1 \mathrm{~g}$ de ácido graxo produzido. Dentre os suportes avaliados, o maior índice de acidez ao longo do tempo foi obtido para a enzima LCR imobilizada em carvão ativado.

\subsection{Eficiência de imobilização}

A eficiência de imobilização $(\eta)$ foi calculada ao longo de $8 \mathrm{~h}$ de imobilização e os resultados apresentados na Figura 2, sendo os valores médios mostrados na Tabela 1 .

O carvão ativado, entre os suportes avaliados, foi o que apresentou uma $\eta$ elevada, muito próxima da máxima eficiência de imobilização, alcançando uma média de $89 \%$ durante as $8 \mathrm{~h}$ de análises. O carvão ativado também foi o que apresentou superfície mais irregular, maior área superficial e grande número de poros, o que deve ter favorecido as interações com a lipase durante o processo de imobilização.

Figura 2. Eficiência de imobilização $(\eta)$ de LCR em diferentes suportes ao longo de $8 \mathrm{~h}$.

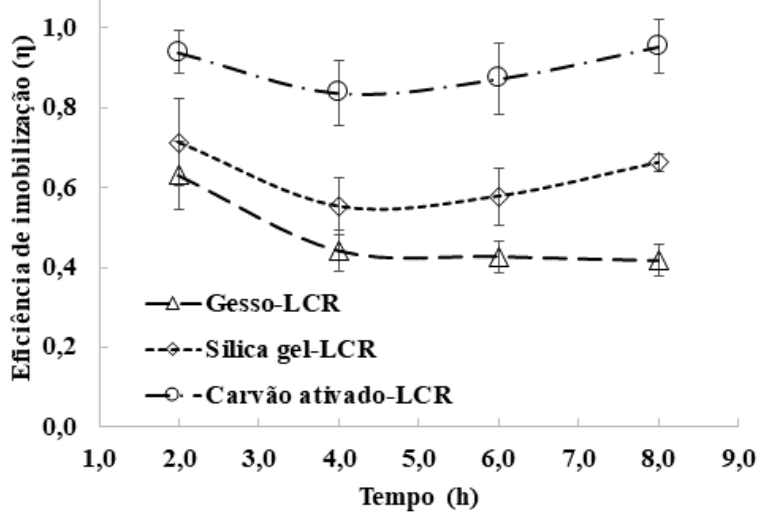

Tabela 1. Valores médios da eficiência de imobilização ( $\eta$ ) de LCR em diferentes suportes durante $8 \mathrm{~h}$.

\begin{tabular}{lc}
\hline Suporte/Enzima & $\eta(\%)$ \\
\hline Carvão ativado-LCR & 89 \\
Sílica gel-LCR & 62 \\
Gesso-LCR & 48 \\
\hline
\end{tabular}

\subsection{Ponto de carga zero}

Uma vez que a adsorção e especificidade enzimática baseia-se nas interações entre a molécula do substrato/inibidor e o sítio ativo da enzima, como, por exemplo, as ligações de hidrogênio, as interações de van der Waals e as interações eletrostáticas (enzima e substrato/inibidor), uma investigação mais aprofundada sobre as características deste suporte foi realizada, a fim de compreender acerca da maior atividade hidrolítica apresentada pelo complexo carvão ativado-LCR.

A partir dos resultados que indicaram que o carvão ativado foi o melhor suporte de imobilização da LCR em relação aos outros suportes avaliados, procedeu-se à determinação do seu ponto de carga zero (Figura 3).

Os resultados demostraram que o pHPCZ do carvão ativado se encontra na faixa de $\mathrm{pH}$ ótimo das lípases, que está entre 6,0 e 8,0 (KAMINI et al., 2000; SHU et al., 2006; NAWANI et al., 2007). Este fato contribui para a manutenção da atividade hidrolítica do complexo carvão ativado-LCR, e também sugere que as interações hidrofóbicas prevaleceram no processo de imobilização (RODRIGUES et al., 2008).

A partir dos dados de $\Delta \mathrm{pH}\left(\mathrm{pH}_{\text {Final }}-\right.$ $\mathrm{pH}_{\text {Inicial }}$ ) versus $\mathrm{pH}_{\text {Inicial, }}$ (Figura 3 ) foi possível determinar o valor do pHPCZ para o carvão ativado, encontrado no ponto onde $\Delta \mathrm{pH}$ é igual a zero, e neste ponto a superfície se comporta como um tampão. $\mathrm{O}$ pH PCZ obtido para o carvão ativado foi de aproximadamente 6,9 , isto indica que, quando o carvão está em contato com uma solução líquida com $\mathrm{pH}$ abaixo deste valor, a carga superficial do carvão será positiva e favorecerá a adsorção de ânions. Ao contrário, se o pH estiver acima deste valor a superfície está carregada negativamente, favorecendo a adsorção de cátions.

Esta hipótese se torna relevante quando se considera os múltiplos estados conformacionais da LCR, em especial no chamado estado fechado, em que a enzima 
apresenta um loop que se estende sobre o sítio ativo e o sequestra do ambiente da solução, sendo o lado desse loop voltado para o solvente menos hidrofílico que o resto da superfície enzimática, com cadeias hidrofóbicas importantes (CYGLER e SCHRAG, 1999; SUBROTO et al., 2020).

Segundo SCHUBERT e HÜSING (2005), o ponto de carga zero da sílica gel situa-se entre os pH de 3 e 5. FAGNANI et al. (2017) verificaram que o ponto de carga zero da sílica gel igual a 4,7.

Os valores para o $\mathrm{pH}_{\mathrm{PCZ}}$ dos suportes e de atividade enzimática obtidos neste trabalho sugerem que a LCR apresenta maior afinidade por suporte com superfícies neutras, ou seja, em suportes com pHPCZ mais próximo de 7 , resultando no processo de imobilização com melhor estado conformacional para a LCR imobilizada e com mínima redução da atividade hidrolítica do complexo suporteLCR.

Figura 3. Determinação do $\mathrm{pH}_{\mathrm{PCZ}}$ para o carvão ativado.

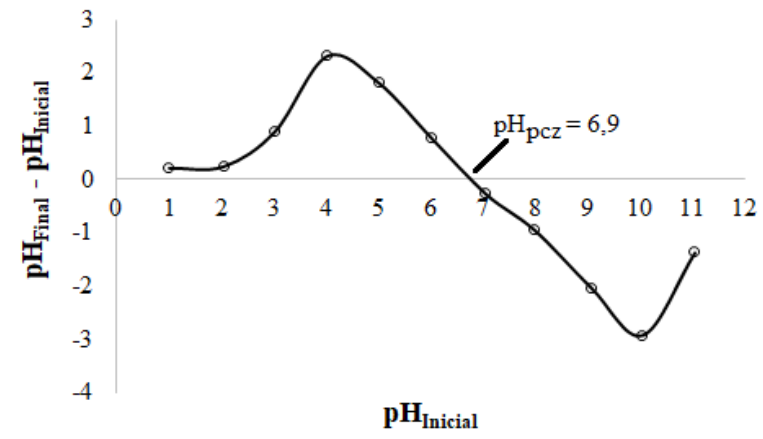

\subsection{Análises morfológicas}

Visando uma maior compreensão sobre os resultados de imobilização, os adsorventes foram caracterizados morfologicamente e os resultados apresentados nas Tabelas 2, 3 e 4 .

Características semelhantes para este adsorvente são apresentadas por Da Luz et al., $\left(2013^{\mathrm{a}}\right.$; 2013b) e De Souza et al. (2012). Segundo o fabricante, este carvão ativado possui um alto número de iodo $\left(>0,95 \mathrm{~g} \mathrm{I}^{2} / \mathrm{g}\right)$, que segundo El-Hendawy et al. (2001) este parâmetro está relacionado a superfície interna do material poroso, onde $0,001 \mathrm{~g}$ de iodo adsorvido corresponde a $1 \mathrm{~m}^{2} \mathrm{de}$ superfície interna.

Tabela 2. Características morfológicas do carvão ativado.

\begin{tabular}{lc}
\hline \multicolumn{1}{c}{ Característica } & Valor \\
\hline Diâmetro de partículas $(\mathrm{m})$ & $0,00071-0,00168$ \\
Área superficial $\left(\mathrm{m}^{2} / \mathrm{g}\right)$ & 788,0 \\
Volume de poro $(\mathrm{mL} / \mathrm{g})$ & 0,373 \\
Tamanho dos poros $(\mathrm{m})$ & $18 \times 10^{-10}-1355 \times 10^{-10}$ \\
\hline
\end{tabular}

Tabela 3. Características morfológicas da sílica gel.

\begin{tabular}{lc}
\hline \multicolumn{1}{c}{ Característica } & Valor \\
\hline Diâmetros de partículas $(\mathrm{m})$ & $0,000063-0,0002$ \\
Área superficial $\left(\mathrm{m}^{2} / \mathrm{g}\right)$ & 500,0 \\
Volume de poro $(\mathrm{mL} / \mathrm{g})$ & 0,75 \\
Tamanho dos poros $(\mathrm{m})$ & $60 \times 10^{-10}$ \\
\hline *Fonte: Fabricante &
\end{tabular}

Tabela 4. Características morfológicas do gesso beta comercial.

\begin{tabular}{lc}
\multicolumn{1}{c}{ Característica } & Valor \\
\hline Diâmetros de partículas $(\mathrm{m})$ & 0,2236 \\
Área superficial $\left(\mathrm{m}^{2} / \mathrm{g}\right)$ & 4,67 \\
Volume de poro $(\mathrm{mL} / \mathrm{g})$ & 0,02314 \\
Tamanho dos poros $(\mathrm{m})$ & $149,27 \times 10^{-10}$ \\
\hline *Fonte: Melo (2012) &
\end{tabular}

As características da superfície do carvão ativado foram analisadas morfologicamente através de micrloscopia eletrônica de varredura (MEV), obtendo-se imagens com ampliação de 250 a 1200 vezes, sendo estas apresentadas na Figura 4.

Estas micrografias demonstram que o carvão ativado apresenta uma superfície irregular e heterogênea, com grande número de poros. Além disso, verifica-se a presença de grande quantidade de clorpos globulares com aglomerações pontiagudas e cônicas. Uma superfície com essas características pode favorecer interações com lipases devido à maior superfície de contato do suporte e as maiores possibilidades de interações hidrofóbicas (RAO et al., 2020). 
Figura 4 - Micrografias do carvão ativado com ampliação de (a) 250x, (b) 800x, (c) 1200x.

a)

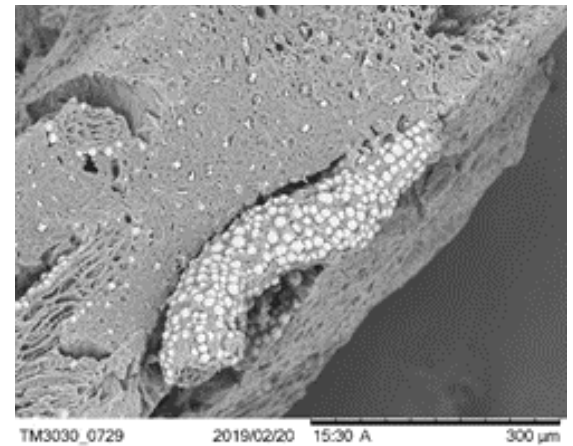

b)

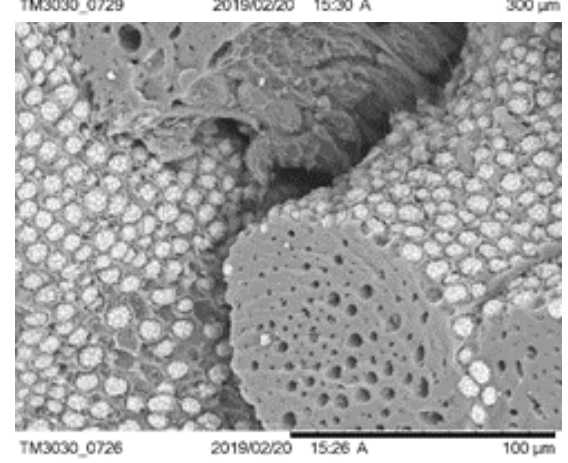

c)

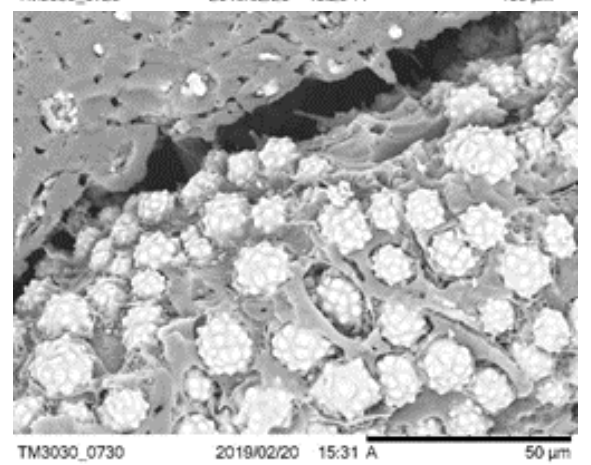

\subsection{Produção de biodiesel e análise de cromatografia de camada delgada (CCD)}

A análise de cromatografia de camada delgada é um método de análise utilizado na separação dos constituintes de uma mistura, onde sob uma fina camada de adsorvente (alumina, sílica, etc.) depositada sobre uma superfície plana os constituintes da mistura migram de forma diferenciada envolvendo as interações intermoleculares entre os constituintes, o eluente e o adsorvente utilizado (Collins et al. 1997). O parâmetro mais importante a ser considerado nesta análise é o fator de retenção $\left(R_{f}\right)$, o qual é expresso pela razão entre a distância percorrida pela substância em questão e a distância percorrida pela fase móvel. Os valores ideais para $R_{f}$ estão entre 0,4 e 0,6 (DEGANI, CASS, VIERA 1998).

$\mathrm{Na}$ Figura 5 é apresentado o cromatograma da matéria-prima (esquerda) e do produto (direita) da reação de transesterificação do óleo de soja utilizando o complexo carvão ativado-LCR. Ao avaliar a análise qualitativa fornecida pela CCD verifica-se os seguintes fatores de retenção (Rf) e ordem de eluição dos prováveis constituintes (acilgliceróis): monoacilglicerol (MAG, $R_{f}=0,20$ ), diacilglicerol (DAG, $R_{f}=$ $0,36)$ e triacilglicerol (TAG, $R_{f}=0,63$ ). Estes fatores de retenção estão relacionados com o número de carbono equivalente dos acilgliceróis. Também é possível verificar que a amostra de biodiesel não apresentou quantidades detectáveis de matéria-prima, porém a presença dos acilgliceróis indicam uma reação de transesterificação incompleta. No entanto, esta análise evidenciou a conversão da matéria-prima no produto desejado, sendo este, compatível com o biodiesel obtido a partir do óleo de soja.

Figura 5 - Placa cromatográfica da matériaprima (esquerda) e do produto (direita) da reação de transesterificação do óleo de soja pelo complexo carvão ativado-LCR, eluido em ácido acético: acetato de etila: n-hexano $(0,1: 1: 200, \mathrm{v} / \mathrm{v})$ e revelado em vapor de iodo.

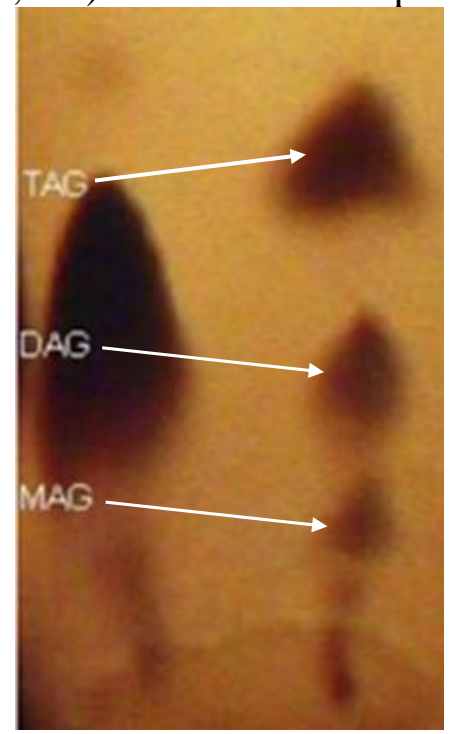

Vol. 18, N. 01 (2021) 


\section{ConClusões}

Os resultados deste trabalho contribuíram para aprofundar os conhecimentos sobre os processos de imobilização por adsorção de lípases fúngicas sobre suportes heterogênicos, bem como, sobre os fatores que influenciam este processo e na atividade enzimática do complexo suporte-enzima que podem ser utilizados como catalisadores para produção de biodiesel. Os resultados indicaram que todos os complexos enzima-suporte apresentaram atividade hidrolítica derivada da LCR após sua imobilização.

O carvão ativado foi o suporte que demonstrou maior eficiência de imobilização e atividade hidrolítica da enzima imobilizada, seguido pela sílica gel e o gesso. Este resultado indica que o complexo carvão ativado-LCR apresenta potencial para biocatálise visando à produção de biodiesel.

Os resultados obtidos pela cromatografia em camada delgada (CCD) proporcionaram a visualização do produto (ácido graxos) de maneira eficiente, evidenciando a conversão da matéria-prima no produto desejado.

A caracterização do carvão ativado sugere que as interações por ligações não covalentes hidrofóbicas foram a força motriz do processo de imobilização da LCR, e estas proporcionaram uma maior performance e eficiência de imobilização para este suporte. Adicionalmente, a superfície irregular e heterogênea, que apresenta grande número de poros e grande quantidade de corpos globulares com aglomerações pontiagudas e cônicas pode ter favorecido a ligação enzimática por aumentar sobremaneira a superfície de contato enzima-suporte.

Os resultados mostram que o complexo carvão ativado- LCR se apresentacomo uma alternativa potencial para o desenvolvimento de tecnologias que visam a diminuição dos custos, aumento da eficiência e que causem menores impactos ambientais na produção de biodiesel.

\section{AgRAdeCIMENTOS}

À Fundação de Amparo à Pesquisa do Estado de Minas Gerais - FAPEMIG (PPM00477-10), à Universidade Federal de São João Del-Rei (UFSJ), à Universidade Federal de Santa Catarina (UFSC), à Coordenação de Aperfeiçoamento de Pessoal de Nível Superior (CAPES) e ao Conselho Nacional de Desenvolvimento Científico e Tecnológico $(\mathrm{CNPq})$ pelo apoio financeiro para o desenvolvimento da pesquisa.

\section{REFERÊNCIAS}

ABREU, P. S. M. Análise econômica dos processos de produção do biodiesel de soja: rota química x rota enzimática. 2013. 138p. Dissertação (Mestrado em Engenharia de Processos Químicos e Bioquímicos) - UFRJ. Rio de Janeiro, 2013.

ALI, Y.; HANNA, M. A. Alternative diesel fuels from vegetable oils. Bioresource Technology. v. 50, n. 2, p. 153-163, 1994.

ARANTES, G. M. Uma perspectiva computacional sobre catálise enzimática. Química Nova, São Paulo, v. 31, n. 2, p. 377383, 2008.

ATADASHI, I. M.; AROUA, M. K.; ABDUL AZIZ, A. R.; SULAIMAN, N. M. N. The effects of catalysts in biodiesel production: A review. Journal of Industrial and Engineering Chemistry. v. 19, n.1, p. 14-26, 2013.

BARBOSA, A. S.; SILVA, M. A. O.; CARVALHO, N. B.; MATTEDI, S.; IGLESIAS, M. A.; FRICKS, A. Y.; LIMA, A. S.; FRANCESCHI, E.; SOARES, C. M. F. Imobilização de lipase por encapsulação em sílica aerogel. Química Nova, São Paulo, v. 37, n. 6, p. 969-976, 2014. 
BASSO, A.; SERBAN, S. Industrial applications of immobilized enzymes - A review. Molecular Catalysis, v. 479, 110607, 2019.

BRUNO, L. M.; FILHO, J. L. L.; CASTRO, H.F. Comparative Performance of Microbial Lipases Immobilized on Magnetic Polysiloxane Polyvinyl Alcohol Particles. Brazilian Archives of Biology and Technology, v. 51, n. 5, p. 889-896, 2008.

BP p.1.c. BP Statistical Review of World Energy 2019, 68th edition, June, 2019. 64 p.

CANTONE, S.; FERRARIO, V.; CORICI, L.; EBERT, C.; FATTOR, D.; SPIZZO, P.; GARDOSSI, L. Efficient immobilisation of industrial biocatalysts: criteria and constraints for the selection of organic polymeric carriers and immobilisation methods. Chemical Society Reviews, v. 42, n. 15,p. 6262-6276, 2013.

CAMPOS, N. F.; SANTOS, J. H. L.; BARBOSA, C. M. B. M.; DUARTE, M. M. M. B. Caracterização de carvão ativado da palha de coqueiro e avaliação do uso na remoção de ácidos naftênicos presentes em mistura modelo de querosene de aviação. In: XX Congresso Brasileiro de Engenharia Química, 2014, Florianópolis, p. 1-8.

CARDOSO, C. L.; MORAES, M. C.; CASS, Q. B. Imobilização de enzimas em suportes cromatográficos: uma ferramenta na busca por substâncias bioativas. Química Nova, São Paulo. v. 32, n. 1, p. 175-187, 2009.

CARDOSO, T. S.; SANTOS, R. A.; COSTA, R. T. T.; AVIZ, E. O.; ARAÚJO, J. F.; SILVA, A. P.; FREITAS, M. C. C.; CORREIA, L. M. Uma revisão da utilização de catalisadores heterogêneos para a produção de biodiesel. Brazilian Applied Science Review. Curitiba. v. 4, n. 1, p.240-276, 2020.

COLLINS, C. H.; BRAGA, G. L.; BONATO, $P$. S. Introdução a métodos DOI 10.24021/raac.v18i1.5505 cromatográficos. $\quad 7^{\mathrm{a}}$ ed. Campinas-SP: Universidade Estadual de Campinas, 1997. $279 \mathrm{p}$.

CYGLER, M.; SCHARAG, J. D. Structure and conformational flexibility of Candida rugosa lipase. Biochimica et Biophysica Acta, v. 1441, n.3, p. 205-214, 1999.

DA LUZ, A. D.; ULSON DE SOUZA, S. M. A. G; DA LUZ, C.; MELLO, J. M. M.; ULSON DE SOUZA, A. A. Analysis of Competition between Multicomponent BTX Compounds for the Active Site of Adsorption in a Fixed-Bed Column. Industrial \& Engineering Chemistry Research, v.52, n.47, p. 16911-16921, 2013.

DA LUZ, A. D.; ULSON DE SOUZA, S. M. A. G; DA LUZ, C.; REZENDE, R. V. P.; ULSON DE SOUZA, A. A. Multicomponent Adsorption and Desorption of BTX Compounds Using Coconut Shell Activated Carbon: Experiments, Mathematical Modeling, and Numerical Simulation. Industrial \& Engineering Chemistry Research, v. 52, p. 7896-7911, 2013

DALLA-VECCHIA, R.; NASCIMENTO, M. G.; SOLDI, V. Aplicações sintéticas de lipases imobilizadas em polímeros. Química Nova, São Paulo, v. 27, n. 4, p. 623-630, 2004.

DEGANI, A. L. G.; CASS, Q. B.; VIEIRA, P. C. Cromatografia um breve ensaio. Química nova na escola, n. 7, p. 1-5, 1998.

DI SERIO, M.; COZZOLINO, M.; GIORDANO, M.; TESSER, R.; PATRONO, P.; SANTACESARIA, E. From Homogeneous to Heterogeneous Catalysts in Biodiesel Production. Industrial Engineering Chemistry Research, v. 46, n. 20, p. 6379-6384, 2007.

EL-HENDAWY, A. N. A.; SAMRA, S. E.; GIRGIS, B. S. Adsorption characteristics of activated carbon sob tained fromc orncobs. 
Colloids and Surfaces A: Physico chemical and Engineering Aspects, v. 180, p. 209$221,2001$.

ELLIOTT, H. A.; HUANG, C. P. Adsorption characteristics of some $\mathrm{Cu}$ (II) complexes on alumino silicates. Water Research, v.15, n.7, p. 849-855, 1981.

FAGNANI, H. M. C.; DEOLIN, M. E.; BARROS, M. A. S. D.; ARROYO, P. A. Identificação dos mecanismos de sorção em zeólita $\mathrm{NaY}$ e sílica gel. Revista Matéria, v.22, n.3, e11861, 2017.

FANGRUI, M.; MILFORD, A. H. Biodiesel production: a review. Bioresource Tecnology, v.70, n.1, p.1-15, 1999.

FUKUDA, H.; KONDO, A.; NODA, H. Biodiesel fuel production by transesterification of oils. Journal of Bioscience and Bioengineering, v.92, n.5, p.405-416, 2001.

GEBREMARIAM, S. N.; MARCHETTI, J. M. Biodiesel production technologies: review. AIMS Energy, v.5, n.3, p.425-457, 2017.

HASAN, F.; SHAH, A. A.; HAMEED, A. Industrial Applications of Microbial Lipases. Enzyme and Microbial Technology, v.39, n.2, p. 235-251, 2006.

JEGANNATHAN, K. R.; NIELSEN, P. H. Environmental assessment of enzyme use in industrial production-a literature review. Journal of cleaner production, $\mathrm{v}$. 42, p. 228-240, 2013.

KAMINI, N. R.; FUJII, T.; KUROSU, T.; LEFUJI, H. Production, purification and characterization of an extracellular lipase from the yeast. Cryptococcus $\mathrm{sp}$. S-2. Process Biochem. v. 36, n.4 p. 317-324, 2000.

KARAOSMANOĞLU, F.; CIĞIZOĞLU, K. B.; TÜTER, M.; ERTEKIN, S. Investigation of the Refining Step of Biodiesel Production. Energy \&Fuels, v. 10, n. 4, p. 890-895, 1996.

LI, L.; DU, W.; LIU, D.; WANG, L.; LI, Z. Lipase-catalyzed transesterification of rapeseed oils for biodiesel production with a novel organic solvent as the reaction médium. Journal of Molecular Catalysis B: Enzymatic, v.43, n.1, p. 58-62, 2006.

MENDES, A. A.; FREITAS, L.; CARVALHO, A. K. F.; OLIVEIRA, P. C.; CASTRO, H. F. Immobilization of a commercial lipase from Penicillium camembertii (Lipase G) by different strategies. Enzyme research,v. 2011, p. 1-8, 2011.

MELO, D. C. P. Processo de calcinação da gipsita/resíduo em um forno rotativo contínuo para a produção de gesso beta reciclável. 2012. 177 p. Tese de Doutorado (Engenharia Química) - UFP. Recife 2012.

MUSTRANTA, A.; FORSSELL, P,; POUTANEN, K. Applications of immobilized lipases to transesterification and esterification reactions in nonaqueous systems. Enzyme and Microbial Technology, v.15, n. 2, p. 133-139, 1993.

NAWANI, N.; KAUR, J. Studies on lipolytic isoenzymes from a thermophilic Bacillus sp.: Production, purification and biochemical characterization. Enzyme and Microbial Technology, v. 40, n.4, p. 881-887, 2007.

NGUYEN, H. H.; KIM, M. An Overview of Techniques in Enzyme Immobilization. Applied Science and Convergence Technology, v. 26, n. 6, p. 157-163, 2017.

PARK, J.; REGALBUTO, J. R. A simple, accurate determination of oxide PZC and the strong buffer-ing effect os oxide surfaces at incipient wetness. Journal of Colloid and Interface Science, v. 175, n. 1, p. 239-252, 1995. 
PENCREAC'H, G.; GRAILLE, J.; PINA, M.; VERGER, R. An Ultraviolet Spectrophotometric Assay for Measuring Lipase Activity Using Long-Chain Triacyglycerols from Aleurites fordii Seeds. Analytical Biochemistry, v. 303, n.1, p. 1724, 2002.

PENCREAC'H, G.; BARATTI, J. C. Hydrolysis of p-nitrophenyl palmitate in nheptane by the Pseudomonas cepacia lipase: A simple test for the determination of lipase activity in organic media. Enzyme and Microbial Technology, v. 18, n. 6, p. 417422, 1996.

RAO, A.; SATHIAVELU, A.; MYTHILI, S. Mini review on nano-immobilization of lipase and cellulase for biofuel production. Biofuels, v. 11, n. 2, p. 191-200, 2020.

REGAlbUTO, J.R.; ROBLES, J. The engineering of Pt/Carbon Catalyst Preparation For application on Proton Exchange Fuel Cell Membrane. REU 2004 Summer Program, Catalysis Laboratory, University of Illinois, Progress Report, p. 114, 2004.

ROBLES-MEDINA, A.; GONZÁLEZMORENO, P. A.; ESTEBAN-CERDÁN, L.; MOLNA-GRIMA, E. Biocatalysis: Towards ever greener biodiesel production. Biotechnology Advances, v. 27, n. 4, p. 398408, 2009.

RODRIGUES, D. S.; CAVALCANTE, G. P.; FERREIRA, A. L. O.; GONÇALVES, L. R. B. Immobilization of Candida antarctica Lipase Type B by Adsorption on Activated Carbon. Chemical Biochemical Engineering Quarterly, v. 22, n. 1, p. 125-133, 2008.

SCHUBERT, U.; HÜSING, N. Synthesis of Inorganic Materials. Wiley: Weinheim, 2005. 429 p.
SHU, C. H.; XU, C. J.; LIN, G. C. Purification and partial characterization of a lipase from Antrodia cinnamomea. Process Biochemistry, v. 41, n.3, p. 734-738, 2006.

SILVA, L. L.; CAPELEZZO, A. P.; BESEGATTO, S. V.; CONTO, F.; FERNANDES, S. C.; COSTELLI, M. C.; SAVIO, J.; COLPANI, G. L. Utilização dos resíduos da extração do óleo bruto do café na produção de material adsorvente. Acta Ambiental Catarinense, v. 13, n. 1, p. 1-13, 2016.

SOARES, C. M. F.; CASTRO, H. F.; DE MORAES, F. F.; ZANIN, G. M. Characterization and Utilization of Candida rugosa Lipase Immobilized on Controlled Pore Silica. Applied Biochemistry and Biotechnology, v. 99, n.79, p. 745-757, 1999.

SOUMANOU, M. M.; BORNSCHEUER, U. $\mathrm{T}$. Improvement in lipase-catalyzed synthesis of fatty acid methyl esters from sunflower oil. Enzyme and Microbial Technology, v. 33, n. 1, p. 97-103, 2003.

SOUZA, G. S.; SOUZA, A. S.; CARVALHO, S. D.; SILVA, E. F. Catálise Enzimática: Uma Estratégia Promissora na Produção de Biodiesel. Almanaque Multidisciplinar de Pesquisa. v.1, n. 1, p. 159-169. 2015.

SOUZA, M. A. A. Especificação técnica do biodiesel. In: Câmara, G. M. S. \& Heiffig, L. S. (eds.). Agronegócio de plantas oleaginosas: matérias-primas para biodiesel. ESALQ/USP/LPV, Piracicaba. 7p. 2006.

SUAREZ, P. A. Z.; MENEGHETTI, S. M. P.; MENEGHETTI, M. R.; WOLF, C. R. Transformação de triglicerídeos em combustíveis, materiais poliméricos e insumos químicos: algumas aplicações da catálise na óleoquímica. Química Nova, São Paulo, v.30, n.3, p.667-676, 2007. 
SUBROTO, E.; INDIARTO, R.; PANGAWIKAN, A. D.; HUDA, S.; YARLINA, V. P.; Characteristics, immobilization, and application of Candida rugosa lipase: a review. Food Research, v. 4, n. 5, p. 1391-1401, 2020.

TALHA, N. S.; SULAIMAN, S. Overview of Catalysts in Biodiesel Production. ARPN Journal of Engineering and Applied Sciences, v. 11, n. 1, p.439-448, 2016.

TAN, T.; LU, J.; NIE, K.; DENG, L.; WANG, F. Biodiesel production with immobilized lipase: a review. Biotechnology advances, v. 28, n. 5, p. 628-634, 2010.

THANGARAJ, B.; SOLOMON, P. R.; MUNIYANDI, B.; RANGANATHAN, S.; LIN, L. Catalysis in biodiesel production-a review. Clean Energy, v. 3, n. 1, p. 2-23, 2019.

TISCHER, W.; KASCHE, V. Immobilized enzymes: crystals or carriers? Trends in Biotechnology, v. 17, n. 8, p. 326-335, 1999.

ZARE, A.; BORDBAR, A. K.; JAFARIAN, F.; TANGESTANINEJAD, S. Candida rugosa lipase immobilization on various chemically modified Chromium terephthalate MIL-101. Journal of Molecular Liquids, v. 254, n.15, p.137-144, 2018. 